\title{
EARTHQUAKE RESPONSE STUDY OF MULTI-STORIED RCC BUILDING WITH FVD ON SLOPING GROUND
}

\author{
Mr. S. P. Kotecha, Prof. R. S. Patil, Dr G. R. Gandhe \\ P.G Student, Professor, H.O.D \\ DIEMS Aurangabad-431005
}

Keywords: FVD, RCC, EARTHQUAKE ANALYSIS.

ABSTRACT: Damping performs essential function in format of earthquake resistant structures, which lower the change of the shape when they are subjected to lateral loads or earthquake. In the existing study fluid viscous dampers (FVD) are used to consider the response of RCC buildings on sloping ground. The important challenge of a structure is to endure the lateral loads and switch them to the foundation and to control the story displacement. In order to make structure earthquake resistant, (FVD) have been used. The building is modeled in ETAB 2018 and modeled with different location of FVD. After the study results show building with fluid viscous dampers (FVD) at diagonal bracing shows better performance.

\section{INTRODUCTION}

The viscous fluid dampers are the devices use to control drifting cause by earthquake. This equipment is applied based on distinct building technologies in order to limit the structural responses to the earthquake. Though over the recent years heavy costs have been paid for accurate recognition of force of an earthquake in the research institutes of the world with the purpose of decreasing its damage, the increasing need for more research studies on the effects resulted from the earthquake is felt in the theoretical and laboratorial scales [1].Seismic isolation and energy dissipation are used as protection techniques for reaching the performance objectives of cutting-edge codes. However, many codes encompass layout specs for seismically remote buildings, while there is nonetheless need of accelerated policies for strength dissipation defensive structures. [2]

\subsection{DAMPING}

It is defined as energy loss in the response over the time period. Energy dissipation entails elements such as materials, radiation of soil etc. Clear analysis of damping is required for incorporating its effect to the structure. The structure of response curve does not alternate by damping however the magnitudes are decreased [3]. 


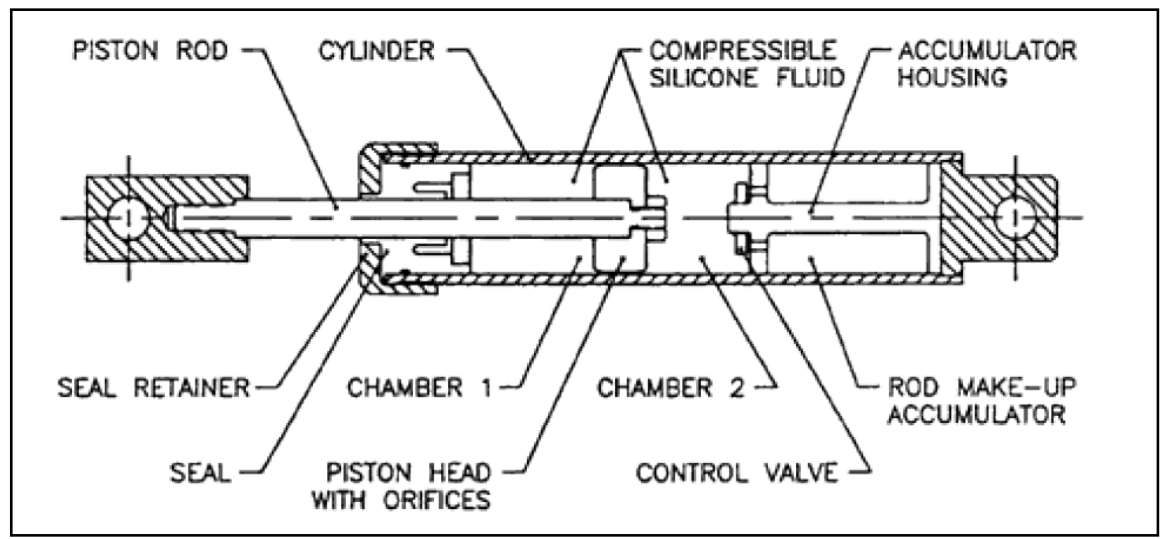

Fig. 1: Schematic view Longitudinal Section of Viscous Damper.

\subsection{FLUID VISCOUS DAMPERS}

The Viscous dampers are passive energy dissipation device which is added to structure to increase the effective stiffness of new and existing buildings. They are very robust material and energy is transferred by piston and absorbed or vanishes by silicone-based fluid flowing between the piston-cylinder arrangements. In this damper, by using viscous fluid inside a cylinder, energy is dissipated. Due to ease of installation, adaptability and coordination with other members also diversity in their sizes, viscous dampers have many applications in designing and retrofitting.

\section{SYSTEM DEVELOPMENT}

\subsection{Problem Statement for square building}

The $\mathrm{G}+10$ building having $(13 \mathrm{~m} \times 13 \mathrm{~m})$ in plan and on sloping ground is taken for study having; four models are studied here as first one is without any damper fixed at base, second one is also without dampers having hinge base, third one is with roller base and viscous fluid damper (FVD) at corner portion and at base with fixed footing and fourth one is with hinge base and viscous fluid damper (FVD) at corner portion.

Table 3.2: Square Building Properties

\begin{tabular}{|l|c|}
\hline \multicolumn{2}{|c|}{ BUILDING PROPERTIES } \\
\hline Grade Of Concrete & M25 \\
\hline Grade Of Steel & FE- 500 \\
\hline Column Size & $250 \times 600$ \\
\hline Beam Size & $250 \times 450$ \\
\hline Earthquake Zone & V \\
\hline Slab Thickness & $150 \mathrm{MM}$ \\
\hline Soil Type & MEDIUM TYPE 3 \\
\hline Storie Height & $3.5 \mathrm{M}$ \\
\hline
\end{tabular}




\begin{tabular}{|l|l|} 
Single Damper Resitance & $250 \mathrm{Kn}$ \\
\hline
\end{tabular}

Table 3.3: Designation of model

\begin{tabular}{|c|c|}
\hline Type of structure & Designation \\
\hline \multicolumn{2}{|l|}{ 1. Square shape Building } \\
\hline a. Normal building fix base & KSD1 \\
\hline b. Normal building hinged base & KDS2 \\
\hline c. Base + diagonal dampers bldg & KDS3 \\
\hline d. Diagonal dampers bldg hinge base & KDS4 \\
\hline
\end{tabular}

While applying the loads to the structure we consider only the external loads which are actually acting on the members neglecting its self-weight because ETABS 2018 V19 automatically takes the members self-weight. Earthquake loading is calculated by software itself according zone and soil type.

Table 4.1: Loading On Building

\begin{tabular}{|l|c|}
\hline \multicolumn{2}{|c|}{ LOADING } \\
\hline Dead load (brick load/wall load) & $10 \mathrm{KN} / \mathrm{M}$ \\
\hline Live load & $3 \mathrm{KN} / \mathrm{M} 2$ \\
\hline Floor load & $1.5 \mathrm{KN} / \mathrm{M} 2$ \\
\hline
\end{tabular}

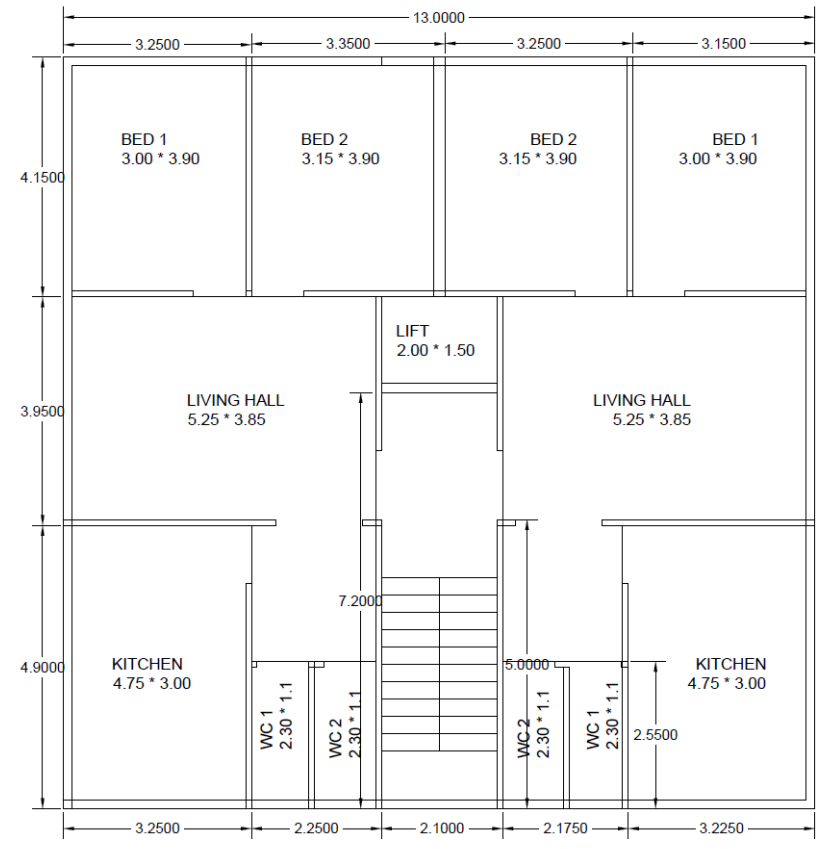

Figure 2: AutoCAD plan for rectangular shape building 


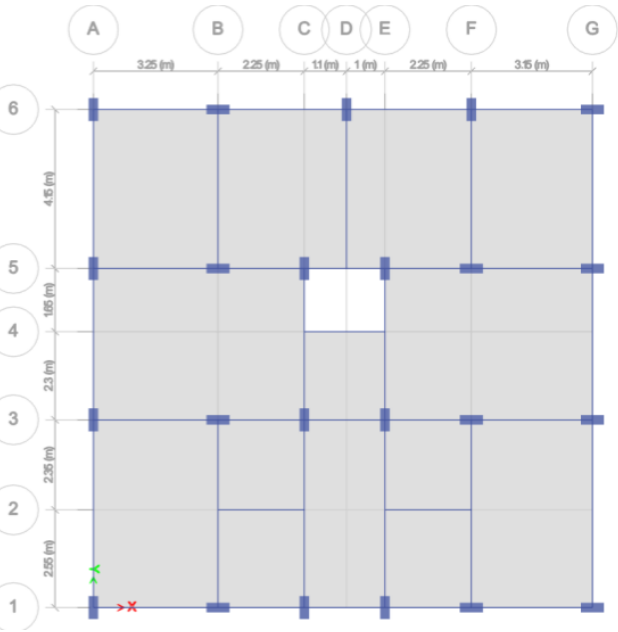

Fig 3: Plan of G+10 building
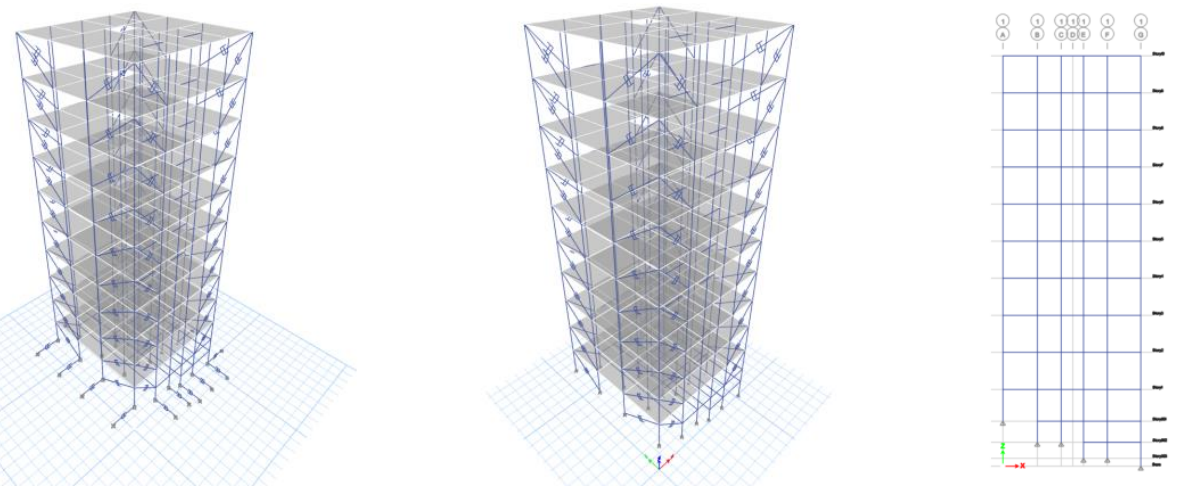

Fig 4: Elevations of $\mathbf{G + 1 0}$ building

\section{Response Spectrum Analysis}

In order to perform the seismic analysis and design of a structure to be built at a particular location, the actual time history record is required. However, it is not possible to have such records at each and every location. Further, the seismic analysis of structures cannot be carried out simply based on the peak value of the ground acceleration as the response of the structure depend upon the frequency content of ground motion and its own dynamic properties. To overcome the above difficulties, earthquake response spectrum is the most popular tool in the seismic analysis of structures. There are computational advantages in using the response spectrum method of seismic analysis for prediction of displacements and member forces in structural systems. The method involves the calculation of only the maximum values of the displacements and member forces in each mode of vibration using smooth design spectra that are the average of several earthquake motions.

For the analysis, for Zone IV, medium soil and $0.05 \%$ of damping the response spectrum graph is shown in figure 


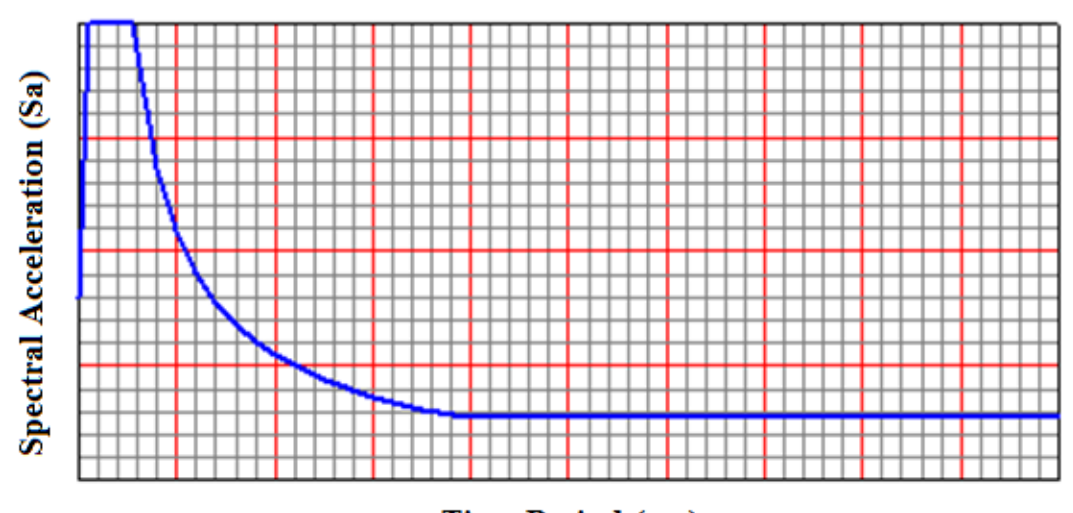

Time Period (sec)

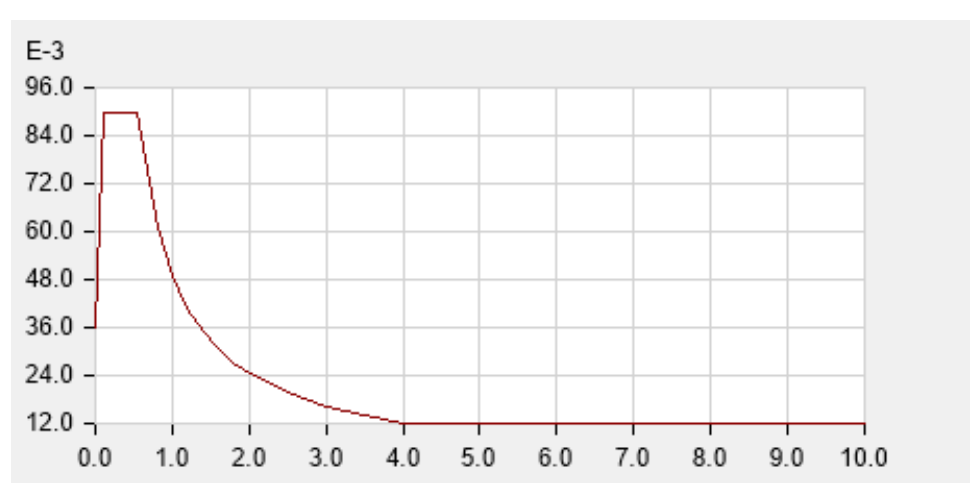

Fig 5: Plot of Response Spectrum Curve ZONE-V.

\section{RESULTS}

Analytical studies were performed in order to investigate the performance of the building with various location of FVD. To analyze the performance results considered are maximum story displacement, base shear restivity 


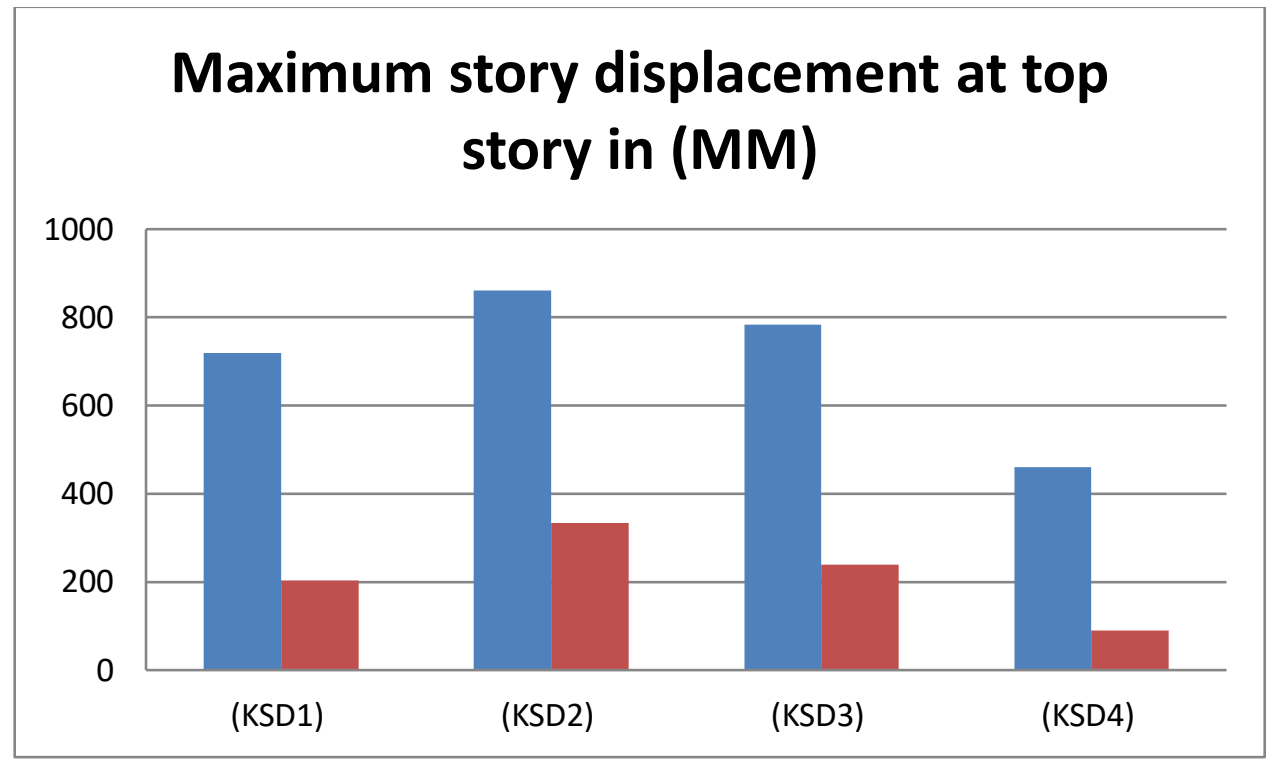

Fig 6: Max story displacement at top story in (MM)

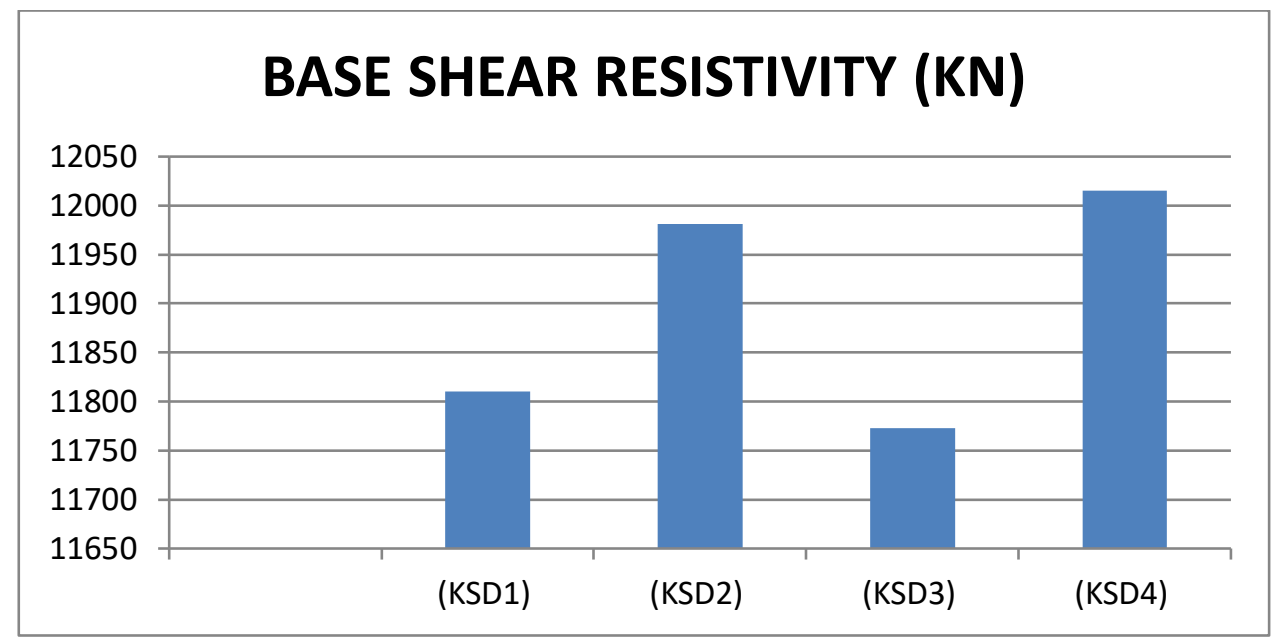

Fig 7: Base shear resistivity (KN) 


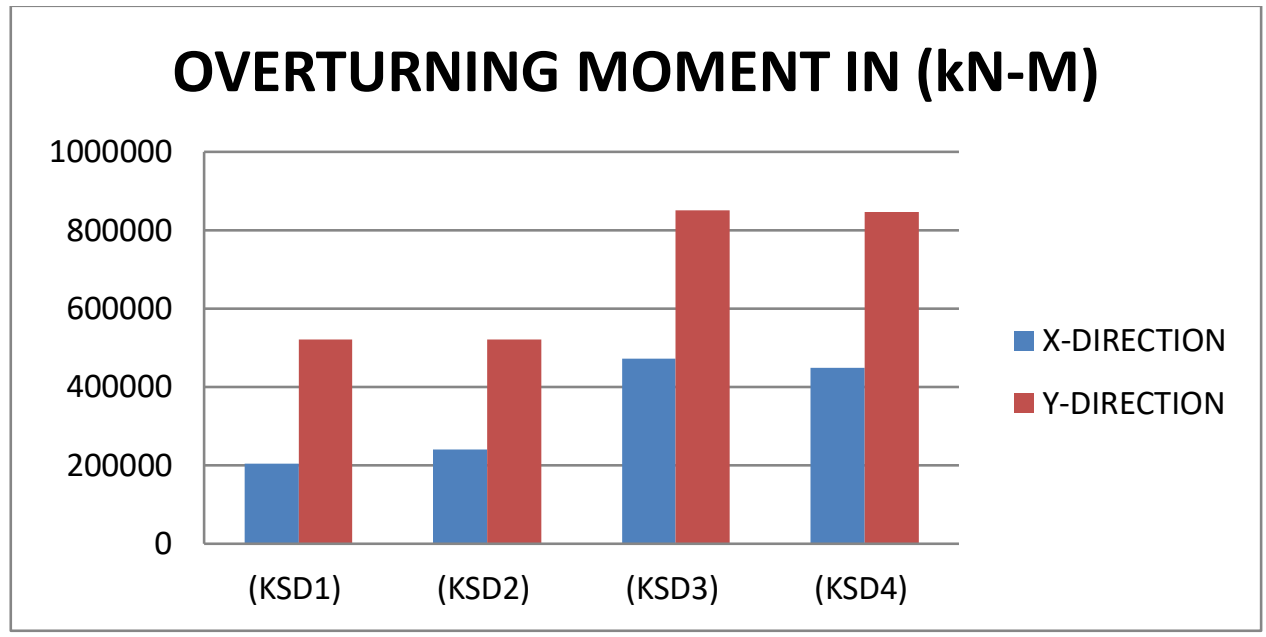

Fig 8: Overturning Moment (kN-M).

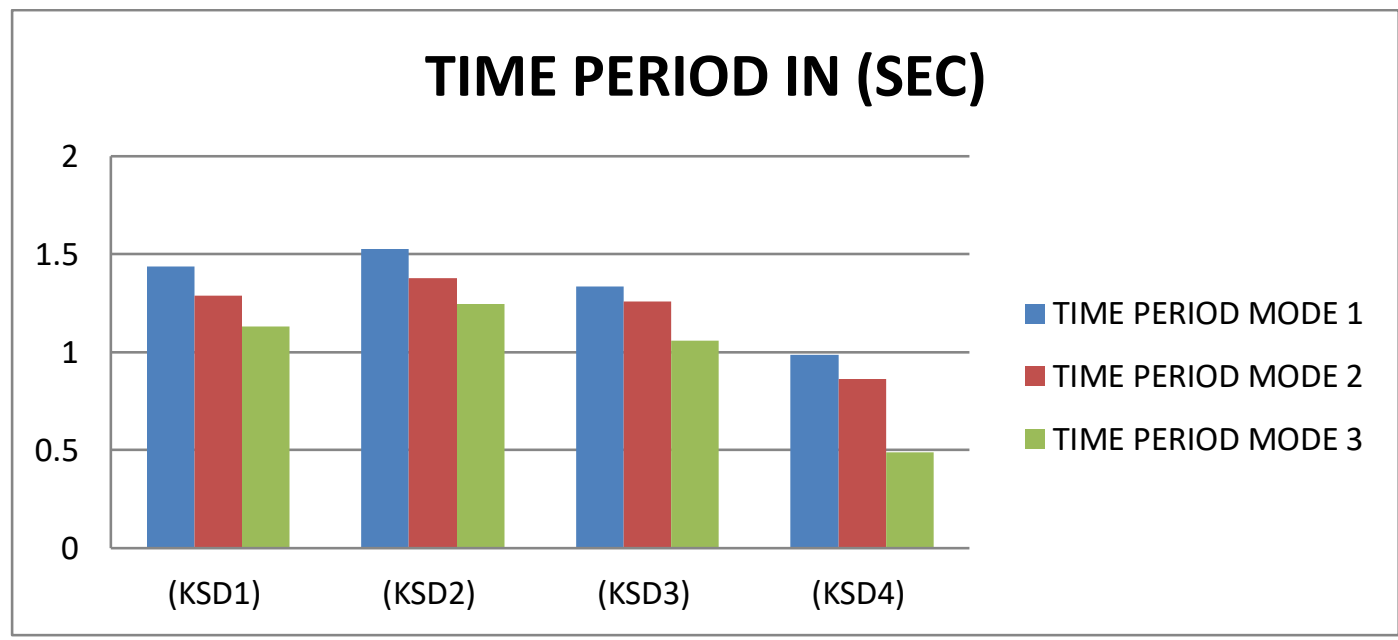

Fig 9: TIME PERIOD OF SQARE SHAPE BUILDING

1. From figure 9 it is observed that Time period for KSD4 building having diagonal dampers only had least time period than other any building.

2. Time period for KSD3 building have second list time period followed by KSD1 and KSD2.

3. The time period is inversely proportional to the frequency which relates building stiffness as decreases in the time period it will increase the stiffness of building.

\subsection{OBSERVATIONS}

I. From figure 6 it is observed that maximum story displacement for building having VFD only at diagonal portion (KSD4) less as compare to other building. 
II. From figure 7 base shear restivity is more in case of building KSD4 than other building.

III. From figure 8 it is found that building KSD3 having more OVERTURNING MOMENT RESISTANCE than building KSD4 followed by KSD2 and KSD1.

\section{CONCLUSION}

From above observation it is found that performance of building KSD4 having diagonal dampers only and hinge base gives overall better performance than other building on sloping ground.

\section{REFERENCE}

1. M. R. Arefi, "A study on the damping ratio of the viscous fluid dampers in the braced frames," vol. 3, no. 4, pp. 1223-1235, 2014.

2. J. Marti, M. Crespo, and F. Martinez, "Seismic Isolation and Protection Systems," Seism. Isol. Prot. Syst., vol. 1, no. 1, pp. 125-140, 2010.

3. M. K. Muthukumar G, “Analytical modeling of damping," Indian Concr. J., vol. 88, no. 4, 2014.

4. MehrtashMotamedi, FariborzNateghi-A. "Study on mechanical characteristics of accordion metallic damper" Journal of Constructional Steel Research 142 (2018) 68-77.

5. Dargush GF, Cho H, Sant RS. "Cyclic elastoplastic analysis of metallic dampers for seismic energy dissipation." Proceedings of the $7^{\text {th }}$ U.S. National Conference on Earthquake Engineering, Boston, USA. Paper no.1058. 2002. 